\title{
The Impact of Globalization on Cross-Cultural Communication
}

\author{
Lowell C. Matthews and Bharat Thakkar
}

Additional information is available at the end of the chapter

http://dx.doi.org/10.5772/45816

\section{Introduction}

In a global environment the ability to communicate effectively can be a challenge. Even when both parties speak the same language there can still be misunderstandings due to ethic and cultural differences. Over the last decade, there have been countless examples from the business sector that demonstrate how poor communication can lead to poor organizational performance. Understanding the impact of globalization on cross-culture communication is imperative for organizations seeking to create a competitive advantage in the global market. Recent economic challenges further highlight the need for organizations to develop the internal communication capacity necessary to control and monitor external threats. As society becomes more globally connected the ability to communicate across cultural boundaries has gained increasing prominence. Global businesses must understand how to communicate with employees and customers from different cultures in order to fulfill the organization's mission and build value for stakeholders. The use of technology has had a profound impact on how businesses communicate globally and market their products and services. However, with the advancements in technology organizations must still be cognoscente of the culture nuisances that can potentially present obstacles in trying to increase profits and market share. According to Genevieve Hilton, "cultural proficiency doesn't mean memorizing every cultural nuance of every market. It's knowing when to listen, when to ask for help, and when - finally - to speak" [1].

For companies involved in global business operations the relationship of managers and subordinates in multinational firms is important. In research conducted by Thomas and Ravlin [2] it was found that participants to whom nationality was more important indicated lower perceptions of similarity with the manager, lower intentions to associate, and lower perceptions of managerial effectiveness. The results of the study strongly indicate that teaching members of different cultures to behave like each other is an ineffective approach 
to improving intercultural interactions in business settings [2]. Focus should be placed on using individual differences to create innovation. Training and development of individuals involved in intercultural interactions should involve more than simply promoting cultural adaptation

Communication is vital for businesses to effectively explain how their products and services differ from their competitors. Companies that are successfully able to communicate crossculturally have a competitive advantage because they can devote more time and resources to conducting business and less time on internal and external communication issues [1]. Communication is necessary for individuals to express themselves and to fulfill basic needs. The same holds true for businesses, governments, and countries. Without the ability to communicate and understand each other, there would be chaos. Communication that is based on cultural understanding is more apt to prevent misunderstandings caused by personal biases and prejudices.

To illustrate the importance of communication on building relationships globally consider the example of the United States and South Korea. The relationship between these two countries is one built upon a rich history. In 1884, the United States government became the first foreign entity to purchase property in Korea [3]. Before this time no foreigner was permitted to live inside Seoul. Despite significant cultural differences, South Korea and the United States have been able to develop a communication process that other countries seek to replicate. The American Chamber of Commerce in Korea was established in 1953 with the chief purpose to promote the advancement of trade and commerce between Korea and the United States. Article II of the Chamber's constitution outlines the following six objectives [4]:

1. To promote the development of commerce between the United States of America and Korea;

2. To promote measure calculated to benefit and protect the interests in Korea of member companies and citizens of the United States;

3. To represent, express, and give effect to the opinions of the Chamber business community of the United States regarding trade, commerce, finance, industry, and related questions;

4. To collect, evaluate, and disseminate among its members statistical and other information concerning commerce or other undertakings of interest to them;

5. To associate and cooperate with other organizations sharing mutual interests;

6. To do any and all other things incidental or related to the attainment of the above objectives.

When countries are able to exchange ideas and communicate in an open society everyone benefits. Kathleen Stephens, U.S. Ambassador to the Republic of Korea, summed it up by saying, "we must use our shared interests and values to compliment and transform each other's growth" [5]. The main purpose of this study is to develop a cross-cultural communication model that can be applied by companies that communicate with employees from different cultures. The aim is to identify the steps that leaders of organizations 
competing in a global environment should consider when communicating to different cultures. This study uses a group a college students participating in the $2^{\text {nd }}$ Korea America Student Conference (KASC) as the main research source for creating the model. KASC is supported by the International Student Conferences, a non-profit organization located in Washington, D.C., which sponsors student-run educational and cultural exchange programs for university students from the United States, Japan, and Korea [6]. The researchers used a mix of qualitative and quantitative research methodologies to generate the model. A comparative literature review is conducted and organizational examples of Samsung and Hyundai are considered to demonstrate the impact of globalization on cross-culture communication practices. The study also highlights the action research methodology that was employed to design the cross-culture communication model. In conclusion, the $4 \mathrm{C}^{\prime} \mathrm{s}$ Global Leadership Model is introduced to demonstrate how organizational leaders can create innovation in a global environment by managing conflict, communication, creativity, and connectivity.

\section{Literature review}

Research on cross-cultural communication often focuses on understanding how individual differences influence our ability to communicate with others. Since most individuals grow up within a single culture having to interact with others from a different culture or background can represent a challenge [7]. Exposure to different cultures affects our ability to communicate with others in a way that leads to positive outcomes. Fink, Neyer, and Kölling propose that researchers involved in cross-cultural studies should develop an understanding of the interrelations between cultural dimensions, cultural standards, and personality traits [7]. This increased awareness helps an individual to manage their own cross-cultural behavior as well as that of others.

Reza Najafbagy refers to co-orientation, the ability to familiarize all aspects of one's own life in relation to someone of a different culture, as a primary component of intercultural communication [8]. Individuals that have experienced different cultures are more cognizant of how to alter their communication style so that others understand the information they are trying to transfer. Research conducted by Seak and Enderwick revealed the importance of providing cross-cultural communication and training skills for expatriates assigned to foreign locations in particularly, China, Hong Kong, Taiwan, Japan and South Korea [9]. Now more than ever global organizations must ensure that their employees have the skills required to communicate across cultural boundaries. Cross-cultural communication enhances innovation by allowing for collective problem solving and the open dissemination of information [10].

Cohen and Levinthal define the term absorptive capacity as an organization's ability to identify and recognize the value of new external information, absorb it, and implement it into their business operations [11]. Organizations that understand the importance of external information are better able to use their core competencies to create a competitive advantage. Cross-culture communication enhances an organization's absorptive capacity because it provides a new of perspective for satisfying the needs of stakeholders. 
Communication is the life-blood of organizations and must be allowed to flow throughout the entire organization. However, when information flows are random and there is no apparent directive of how to apply the outside knowledge the organization will not benefit [11]. Productivity decreases when organizational leaders are not able to communicate clear and concise expectations. Furthermore, conflict and tension arises when employees do not understand how their personal efforts contribute to the overall success of the organization.

Culture can affect how we perceive the actions of others. Ambassador Stephens gave the example of a "cheerleading group from North Korea that was participating in a sports competition in South Korea. When the group was heading to the venue one of the cheerleaders yelled for the bus stop. She then proceeds to get off the bus in the rain to get a poster of the North Korean leader that was getting wet. Why? Usually, 70\% of Americans would say it was for show. $70 \%$ of Koreans would respond that the cheerleader really felt something" [5]. Our perception of others directly affects how we interpret their behavior and actions. Effective cross-culture communication requires that we base our perceptions on facts and not merely on personal biases and prejudices. The Global Leadership and Organizational Behavior Effectiveness Project (GLOBE) examined cultural values of organizational practices and leadership. The study focuses on identifying cultural influences on leadership and management practices. Some scholars believe that as society becomes more interconnected cultural differences will converge [12]. Even though some convergence may occur over time, countries will still maintain distinct cultural differences that will transcend technology and external influences.

Successful business leaders must be able to balance organizational objectives with external global challenges. As organizations become more interconnected the role of leaders in managing global teams is becoming increasingly important. Being able to navigate through different cultural nuances is a key skill for global leaders. Rabotin defines cultural intelligence as "the ability to interact with others from diverse cultural backgrounds, being aware of our cultural values that drive our attitudes, behaviors, and beliefs" [13]. Regardless of their geographic location leaders must be able to communicate across borders in order to create a competitive advantage and achieve results. It is clearly apparent that physical boundaries are increasingly becoming transparent. A global leader must be aware of their personal cultural biases and be willing to change their opinions by learning from those that are different from them [13].

In research conducted by Choi and Chang it was noted that organizational culture directly impacts the attitudes and motivation of employees towards innovation [14]. The researchers identified three organizational factors of management support, resource availability, and support for learning as key enablers for innovation [14]. All three factors were found to be significantly correlated to implementation, however; only management support was determined to be a significant predictor of innovation [14]. This research supports the conclusion that when employees are fully engaged in the process of innovation success is more likely to be achieved. Organizations must have in place procedures that encourage innovation throughout the entire company. Every employee must feel vested in the company and continually seeking ways to improve processes. 


\section{Methodology}

A qualitative and quantitative research strategy consisting of group observations, interviews, and surveys were used to gather information. These methods are most appropriate because of the complexity involved in studying culture and communication from an individual perspective. By using these methods the researchers were able to ascertain underlying factors that are relevant to understanding the affects of culture on communication when two different groups interact with each other.

Participants were undergraduate and graduate students from South Korea and the United States selected to participate in the $2^{\text {nd }}$ Korea America Student Conference (KASC). Selection to KASC is based on a competitive process. Participation in the study was completely voluntary and students were asked to complete a consent form. A total of 46 students attended KASC and $65 \%$ were female. $52 \%$ of the students resided in South Korea and $48 \%$ in the United States. Interestingly, $73 \%$ of all the students identified Korean as part of their ethnicity. $91 \%$ of the students were 19 to 23 years of age.

The researchers focused on collecting data from participants to assist in the development of a cross-cultural communication model. The researcher addressed the differences and similarities in communication strategies and the affect on building relationships. Previous research on culture has applied a field-based approach that allows for the exchange of information from multiple sources. The researchers followed a similar structure when participating in KASC over a two-week period.

The role of the researchers was that of consultants that sought to serve as a bridge between the participants and the administrators of the conference. It was important for the researcher to develop a level of trust with the participants quickly. To accomplish this, the researchers assisted staff with administrative tasks during the conference and shared in activities with the participants. The researchers used current programs established by KASC to expand opportunities to exchange information. For example, the researcher attended lectures, group discussions, and roundtable sessions.

The topics discussed during interviews included: a) reasons for participating in KASC, b) individual experiences and interactions with different cultures, c) reactions to changes that occurred during the conference, and d) discussion of how culture affects the communication between American and Korean students. During group observations the researchers focused on key words and phrases that were used by the students and categorized them according to relevant themes. Based on the words and phrases a concept map was created that helped to identify the predictors used in the study.

Five cultural measurements of acceptance, conflict, individualism, risk, and sharing were used to predict the country of residence. Table 1 defines the variables used in the study. The country of residence index was selected as the dependent variable because it is directly affected by culture.

Rigor and validity were addressed by continuously redefining the key issues identified by participants. Participant feedback was vital to this study and was used to form and shape 


\begin{tabular}{|l|l|}
\hline Variable & Definition \\
\hline Acceptance & $\begin{array}{l}\text { A measure of how important it is for an individual to be liked and accepted by } \\
\text { others }\end{array}$ \\
\hline Conflict & A measure of an individual's ability to work with those they do not agree with \\
\hline Individualism & An assessment of how independent an individual behaves in making decisions \\
\hline Risk & $\begin{array}{l}\text { A measure of how open an individual is to trying new things and stepping outside } \\
\text { of their comfort zone }\end{array}$ \\
\hline Sharing & A measure of how willing an individual is to share their opinions and feelings \\
\hline $\begin{array}{l}\text { Country of } \\
\text { residence }\end{array}$ & \begin{tabular}{l} 
The country identified as the primary place of residence \\
\hline
\end{tabular}
\end{tabular}

Table 1. Variables in Cross-Cultural Communication Study

the cross-cultural communication model. The survey that was developed for this study consisted of 23 items that were rated on five point Likert scale with $1=$ strongly disagree to $5=$ strongly agree. Each of the items assessed one of the cultural measurements of acceptance, conflict, individualism, risk, or sharing.

\section{Results}

A multiple regression analysis was conducted to evaluate how well the five independent variables for culture predict the country of residence. The linear combination of culture measures was significantly related to the country of residence index, $F(5,17)=3.57, p<.01$. The sample multiple correlation coefficient was .71, indicating that approximately $51 \%$ of the variance of the country of residence index in the sample can be accounted for by the linear combination of culture measures.

\begin{tabular}{|c|c|c|c|c|}
\hline Model & R & R Square & Adjusted R Square & Std. Error of the Estimate \\
\hline 1 & $.715^{\mathrm{a}}$ & .512 & .368 & .471 \\
\hline
\end{tabular}

a. Predictors: (Constant), Risk, Acceptance, Conflict, Individualism, Share

b. Dependent Variable: Residence

Table 2. Model Summary

The partial regression plots for conflict and sharing exhibit the best correlations for predicting the country of residence index. Table 3 presents indices to indicate the relative strength of the individual predictors. As expected all of the bivariate correlations between the country of residence index were positive.

\begin{tabular}{|c|c|c|}
\hline Predictors & $\begin{array}{c}\text { Correlation between each predictor and } \\
\text { the country of residence index }\end{array}$ & $\begin{array}{c}\text { Correlation between each predictor and the country of } \\
\text { residence index controlling for all other predictors }\end{array}$ \\
\hline Acceptance & .123 & -.140 \\
\hline Conflict & .556 & .558 \\
\hline Individualism & .243 & -.045 \\
\hline Share & .493 & .457 \\
\hline Risk & .021 & -.341 \\
\hline
\end{tabular}

Table 3. The Bivariate and Partial Correlations of the Predictors with the Country of Residence Index 


\section{Cross-cultural communication model}

The purpose of communication is to transfer ideas and knowledge from one entity to the other. The first step in communication is input; someone must say something that is received by someone else. The communication loop is successful when the receiver demonstrates that he or she understands what was being communicated. From an organizational perspective there are many barriers than can impede the flow of communication. These barriers include culture, technology, language, workforce, and environment. For the purpose of this model culture refers to the traditions and customs that are prevalent in the country where each company is located. These traditions and customs influence policies and procedures implemented by businesses. Technology is simply the use of mediums such as email, Internet, text messaging, and cell phones to communicate. When a company does not have experience using a particular technological medium to communicate it may rely on older methods that the other company views as inadequate. Language is what is spoken in the country where the company is located. If the languages of the two companies are different, then one company must learn the other's language or a new language must be created. Workforce refers to the internal structure of the company, including employees, managers, and organizational leaders. Environment refers to the external forces that affect the company. For example, the economy can have an adverse impact on an organization and present an obstacle to cross-culture communication.

As illustrated in Figure 1, when these barriers are eliminated companies are able to experience innovation, reduced conflict, and better dissemination of information. J. KuHyun (personal communication, July 20, 2009) stated "to be successful as a global corporation communication is critical." Without communication organizations will cease to be. The challenge for organizations that must communicate cross-culturally is to ensure that their message is understood the way that it was intended. When communication barriers are not removed it is easy to make assumptions about what is being communicated. Our assumptions of what we thought was being communicated can be very different from the original message. Communication takes effort, it is much easier to sit back and simply assume what we think others are trying to tell us. To actively engage in communication takes time and energy. Organizations must be willing to invest the resources needed to support cross-culture communication.

Successful cross-cultural communication creates a dialogue, a continuous transfer of information. This exchange of information addresses our assumptions and clarifies points we do not understand. It also provides the opportunity for us to ask questions and confirm the information that was received. Having a dialogue reduces conflict because cultural misunderstandings can be dealt with when they arise. The dialogue only occurs when both parties agree to share information and ensure that the transfer of information is not blocked. 


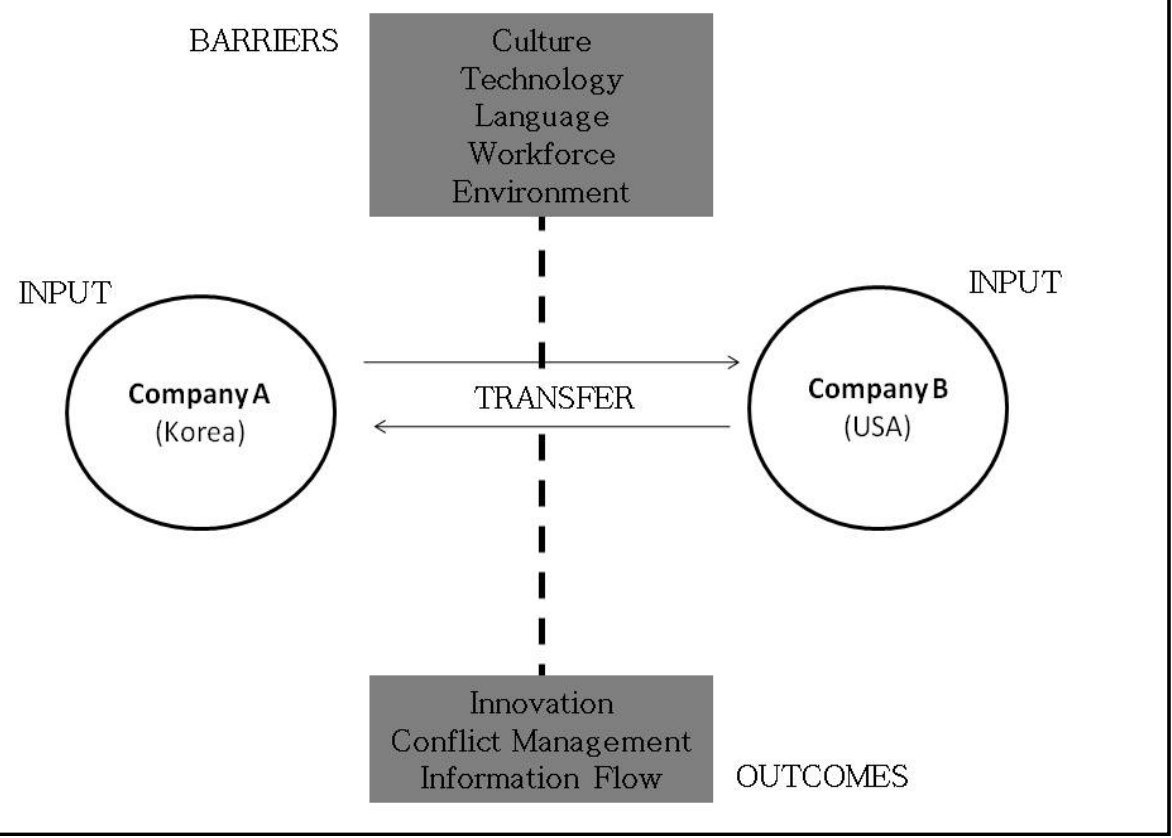

Figure 1. Cross-Culture Communication Model

\section{Samsung and Hyundai}

To illustrate how companies can utilize the cross-culture communication model to improve business practices consider the examples of Samsung and Hyundai. Samsung is unique because of its focus on human resources and risk taking initiatives. The company was founded in 1938 and is the world's largest conglomerate. Samsung is recognized as a global industry leader because of its inner capacity to take advantage of distinct initiatives (J. KuHyun, personal communication, July 20, 2009). It hires a small percentage of non-Koreans inside Korea but employs a higher percentage off non-Koreans outside of Korea. The culture of the organization is very family centric. Decisions occur in a collective atmosphere that allows for communication at all levels of the organization. However, even when decisions are clearly communicated throughout the organization employees may not always show support.

The workforce can represent a barrier to cross-cultural communication when employees feel they are not valued. This presented an issue at Samsung. The expectation was that you stayed at job until your assignment was completed. However, with the increase of younger employees entering the workforce who had different expectations, Samsung had to make a change. Management made the decision to change the workday from five-to-nine to seven- 
to-four [15]. The reason for Samsung's change was to get employees to be more team oriented and more productive. Changing the hours of the workday required employees to work together and it also required managers and supervisors to have a more active role in completing daily tasks. The seven-to-four schedule was a cultural shift that was instigated by new employees entering the company with a different outlook towards work and personal time. Prior to the change, employees were expected to stay on the job until it was completed. With the change the office closed at four and everything stopped. Now employees have to proactively plan their workday in order to ensure that everything is accomplished in a timely fashion.

Samsung has been able to become a global leader because of its commitment to the development of technological capabilities [16]. Management's objective is to "develop technology capabilities for value creation in diverse business areas" that will ultimately support growth in global competition [16]. The focus on innovation requires the sharing of business practices and technology throughout the organization. Samsung must communicate with employees and customers simultaneously to ensure that company objectives are met.

J. Ku-Hyun (personal communication, July 20, 2009) reports that Samsung's competitive advantages include 1) commitment to work that is translated into speed advantages, 2) highly skilled engineers and technicians, and 3) management talent and experience. Samsung has used these competitive advantages to enhance its relationship with customers and expand globally.

Hyundai Motor Company was formed in 1967 and has established itself as company that focuses on quality improvement and innovation [17]. From the small beginning in Seoul, Korea the company has now expanded to more than ten countries including the United States, Canada, India, China, Turkey, Russia, Malaysia, Sudan, Egypt, Indonesia, Iran, and Japan [17]. For this expansion to take place requires effective communication that is able to overcome cultural barriers and accomplish global management initiatives. Research conducted by Wright, Suh, and Leggett revealed that Hyundai's achievement at globalization depended upon its ability to expand international sales as it gained experience in international markets [18]. The move from domestic to global production means Hyundai must operate in "unfamiliar and uncertain economic and cultural contexts" [18].

Over the years Hyundai has learned valuable lessons on the importance of knowing and valuing the needs of its customers. In the early 1990s, Hyundai experienced problems when trying to expand production to Canada. The primary issue was that the company did not adapt the design of the Sonata for North American customers [18]. Consequently, the company lost market share to Toyota's Camry and Honda's Accord. Another important lesson was learned when Hyundai made the decision to start production in Turkey because of the lower cost for workers. Because of the lower wages management decided to use more hand-operated technology instead of the automated manufacturing processes utilized in its domestic plants. As a result, the production rate of the Turkish plant was $25 \%$ lower than 
that in Korea [18]. From these experiences Hyundai learned the importance of researching the culture of a country before making profound business decisions. Cross-culture communication involves adapting organizational policies to fit the context of where business transactions will occur.

Key to Hyundai's success is its corporate philosophy that places the needs of customers as top priority in all business areas. This customer-oriented management style requires organizational leaders to be receptive to new ideas and to think outside the box. To encourage employees to expand their cultural awareness the company encourages threemonth assignments to its overseas sites. For example, when the company was building a site in Alabama it allowed employees to visit and study the culture [19]. The company promotes an employee backpack travel program around the globe where teams of three design their cultural experience. The teams compete for a company sponsorship of 15-day expeditions by writing what they hope to learn [19]. More than 47 teams have traveled to 70 countries, including Peru, Turkey, and Greece [19]. Employees that participate bring back what they learn and share it with their colleagues.

"Hyundai Motor Company is strengthening its position as a global brand, establishing local production systems on a global scale and supplying automobiles that meet the needs and tastes of customers in each specific region" [17]. During a visit to the Asan Plant located in Chungchungnam-do, Korea, it was very apparent of how the company is being innovative. The plant has a production capacity of 300,000 units and utilizes the latest in robotic technology to assemble vehicles (Tour Guide, personal communication, July 27, 2009). One unit is produced every 57 seconds and $100 \%$ of all the welding is completely automated. The Asan plant has 34,000 employees; the average annual salary is $\$ 50,000$. The plant operates two ten-hour shifts and provides numerous incentives for employees that are innovative on the job.

\section{Conclusion}

The researchers proposed attending the 2nd Korea-America Student Conference in order to develop a relationship with participants that have a vested interest in global issues and to define the criteria for the proposed cross-culture communication model by using various qualitative methods. These objectives were accomplished and much insight gained into understanding how culture affects communication.

Samsung and Hyundai are only two examples of organizations that are effectively communicating cross-culturally. Both organizations have been able to learn from their past mistakes and create strategies that support their growth in the global market. The sharing of information makes it possible for other organizations to also benefit from the mistakes made by these organizations.

During one of the group observations a Korean participant stated, "A smile is a basic tool of communication" (personal communication, July 16, 2009). How true it is that a simple smile can break down communication barriers and build bridges of understanding. Cross-culture 
communication is not easy, especially when we are unfamiliar with the receiver of the information. Organizational leaders that have to communicate cross-culturally can use the following steps:

1. Develop clear and concise expectations for how the organization will accomplish its mission;

2. Ensure that employees understand their role in the organization;

3. Be willing to invest time to communicate;

4. Remember that communication is a two-way process, listen before you speak.

"Many misunderstanding have occurred, not only because of mistakes in the usage of words or expressions, but also because of the lack of goodwill and cultural knowledge" [8]. Mistakes are a normal part life and at times if we are not careful our mistakes can have lasting consequences. "We can make mistakes as long as we can correct mistakes. We can get feedback from the global market" [10]. The cross-culture communication model developed from this study provides a mechanism for obtaining feedback from the global market. The model identifies the barriers to cross-culture communication and summarizes the outcomes that can be achieved when these barriers are tackled.

The results of study verified that the five independent variables of acceptance, conflict, individualism, risk, and sharing could be used to predict country residence. A limitation to this study was the small sample size that used. In order to validate the validity and reliability of the study a larger sample size should be used in future studies. The participants of the study were also aware of the need to increase cultural awareness and displayed a desire to gain a deeper understanding of American and Korean relations. The study adds to the current body of knowledge on cross-culture communication by demonstrating the importance of culture in business settings.

Organizational cross-functionality or connectivity is essential to innovation because it brings together a diverse group of people from different functional backgrounds [20]. Management must take steps to ensure that cross-functionality does not create conflict and hinder communication within the team [20]. To effectively generate innovation the level of expertise and individual skill set of each team member must be ascertained. The innovation process is supported when members share a common vision and goal. Research indicates that cross-functional teams are more effective at new produce development that is valued by the customer [21].

Leadership is the foundation to cross-functionality because it provides the oversight and direction necessary for it to work. Leaders that are innovators are receptive to change and value feedback from those around them. They recognize that they cannot be successful unless those around them are successful. For innovative organizations it is necessary for management to develop innovative leaders. This is done by having in place recruitment strategies that target successful applicants that possess the skills necessary to the organization to the next level [22]. There should also be in place a well-developed talentmanagement process that identifies innovators, connects them to the mission of the organization, and provides the necessary internal resources for them to be successful. 


\section{C's Global Leadership Model: Supporting Innovation and Change}

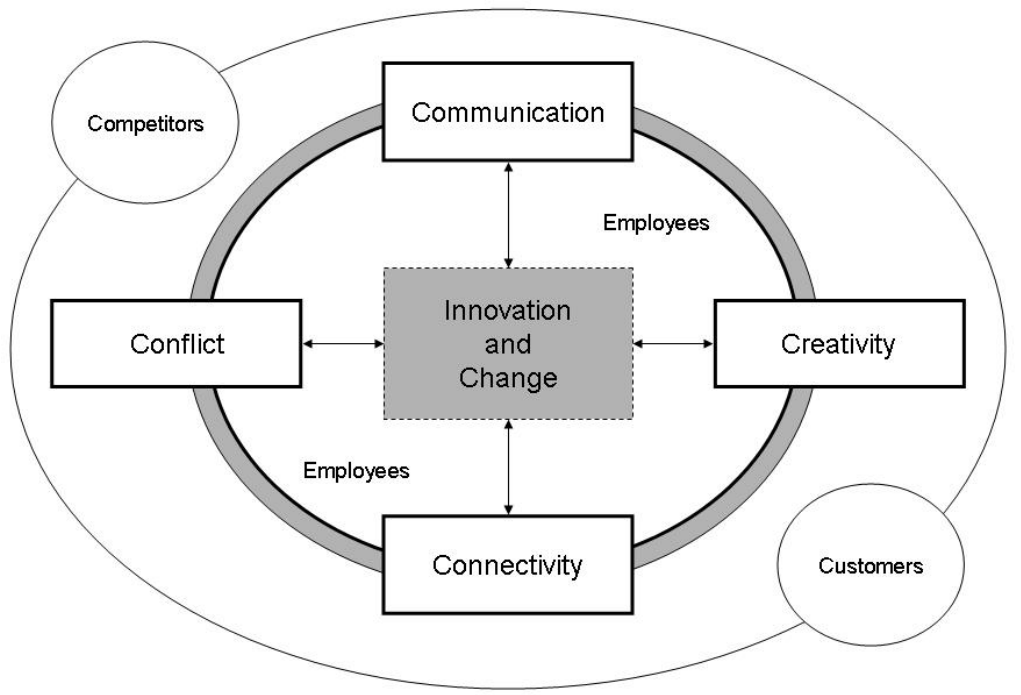

Figure 2. The 4 C's Global Leadership Model

A comparison of leadership strategies between Samsung and Hyundai provides the basis for developing the $4 \mathrm{C}^{\prime}$ s Global Leadership Model that can be employed by organizations to make certain that they have the right person for the job. The model consists of four key factors: communication, conflict, creativity, and connectivity. Being aware of what types of individuals make good global leaders allows the organization to develop HR policies to support recruitment and succession. By creating a pipeline of capable global leaders the organization is able to sustain innovation and change.

Leaders are the main link responsible for harnessing the ideas of employees to create innovation. They must also assess the development of their competitors and the needs of customers. Bringing together individuals from different cultural backgrounds will lead to conflict; however, this does not have to be perceived as a negative. The challenge for global leaders is to use the conflict as a benefit for the organization. Gehani and Gehani define conflict as simply the result of natural differences that occur between people from different backgrounds [23]. Different ideas and views lead to innovation and new products and services. From this perspective leaders should encourage healthy conflict. "Conflict between diverse groups of people can be used to drive the growth of their organizations" [23]. If there were no conflict to spark discussion there would be no innovation.

Communication helps to moderate the relationship between conflict and innovation. This fact is furthermore impacted by the complexity of competing in global environment. Leaders must be aware of the communication styles that are needed when working with 
multicultural teams. The use of the email, conference calls, and other technological innovations to communicate need to be addressed to ensure that all members are able to participate fully. When members feel they are not able to communicate openly innovation is hindered and the organization suffers.

As global competition continues to increase, successful organizations must evolve to meet the changing needs of consumers. Innovation provides the opportunity for organizations to think outside the box and "produce better product, faster, cheaper and more efficiently than competitors [24]. Creativity is directly linked to communication and innovation. Increased attention on innovation has caused organizational leaders to develop systems to manage the process and support the efforts of employees. According to Dooley \& O'Sullivan being able to identify the correct process for implementing innovation will directly impact the success [24]. It is easier to implement innovation when the culture of the organization allows for employee feedback, planning, and evaluation.

Employees play a vital role in innovation. In research conducted by Barnett and Storey it was found that there was a strong connection between learning and innovation in organizations [25]. The researchers studied 220 employees at a manufacturing company, Tensator, located in the United Kingdom. Key to Tensator's success is their ability to integrate succession planning with sustaining innovation [25]. Instead of focusing solely on keeping top management positions filled, the organization seeks to keep the pipeline of skilled laborers in amble supply to support innovation. Tensator follows a growth strategy that centers on "grow-your-own" [25]. This strategy requires the company to continually provide learning and development opportunities for employees to ensure that they remain at the top of their game.

Microsoft is applying a holistic approach to innovation in seeking to compete with Yahoo and Google in the development of search engines [26]. Management is aware they must do more than simply try to catch up with their competitors; they must redesign the way that search engines are viewed and utilized. The holistic approach is further supported by Porter in work done with organizations to help them improve their supply chains [27]. Organizations that use a holistic approach are able to obtain a broader view of how they fit into the global market. Instead of focusing on small segments of their business operations, attention is given to the entire process. This allows for the organization to implement innovation that will create value for customers.

Connectivity is defined as the ability to orchestrate organizational networks to move in the same direction in order to accomplish the company's mission. Employees must feel contacted to the organization and understand how their individual effort contributes to the bottom line. Global leaders must look for opportunities to connect everyone within the organization to the overall goals and objectives. When employees understand the big picture and the direction the organization is taking innovation and change are supported.

The 4 C's Global Leadership Model is designed to provide a basis for organizational leaders to use in mapping out strategies for working globally with multicultural teams. The 
business environment is continually evolving and global leaders must persistently develop new organization strategies to meet global challenges. Although, Samsung and Hyundai both compete in different industries there are parallels that can be gleamed from how they communicate and inspire innovation from their employees. The Cross-Culture Communication Model and 4 C's Global Leadership Model are tools designed to assist organizational leaders to compete in the ever-changing global environment.

The core aspects of global leadership critical to leading innovation and change are vision, communication, and responsibility. In 2008 a group of scholars and business leaders identified twenty-five factors that are important for managers in implementing innovation [28]. Key among them was that management must have a clear vision for the organization. The organizational vision provides a roadmap for employees by defining what the organization hopes to accomplish. Communication is important because it allows for the exchange and refinement of ideas. Effective communication requires that organizations not become bogged down with hierarchal thinking that can typically slow down the communication process. Large organizations must operate like small organizations and be able to respond quickly to organizational and market changes [28].

Successful organizations must focus on goals that are socially responsible [28]. Innovation is not just creating the coolest new gadget but it is creating the coolest new gadget that serves the environment in a sustainable manner. As organizations become more global the focus on corporate social responsibility increases. Organizations can no longer operate within a silo. The actions of one organization can affect many others. According to Westlund it is no longer sufficient for organizations only to make a profit and comply with the law [29]. They must also be socially responsible and give something back to the global community that they serve.

\section{Author details}

Lowell C. Matthews

Southern New Hampshire University, Manchester, NH, USA

Bharat S. Thakkar

CEO, PREMGroup, Inc. and Faculty, College of Business, Walden University

\section{References}

[1] Hilton, G. Becoming culturally fluent. Communication World 2007;24(6) 34-36.

[2] Thomas, D.C., Ravlin, E.C. Responses of Employees to Cultural Adaptation by a Foreign Manager. Journal of Applied Psychology 1995;80 133-146.

[3] Habbi House. The American Embassy Residence Seoul, Korea. 2009.

[4] American Chamber of Commerce in Korea. AMCHAM Korea's Constitution. http://amchamkorea.org/about/constitution.jsp (accessed 15 August 2009).

[5] Stephens, K. Briefing and Informal Meeting. Speech presented at the American Embassy as part of the $2^{\text {nd }}$ Korea America Student Conference, Seoul, Korea. 2009. 
[6] ICS. International Student Conferences. http://www.iscdc.org/ (accessed 17 August 2009).

[7] Fink, G., Neyer, A., Kölling, M. Understanding cross-cultural management interaction. International Studies of Management \& Organization 2006;36(4), 38-60.

[8] Najafbagy, R. Problems of effective cross-cultural communication and conflict resolution. Palestine - Israel Journal of Politics, Economics \& Culture 2008;15/16(4/1), 146-150.

[9] Seak, N., Enderwick, P. The management of New Zealand expatriates in China. International Journal of Human Resource Management 2008;19(7), 1298-1313.

[10] Lim, Wonhyuk. Korea export-oriented industrialization. Lectured presented at Korea Development Institute. Seoul, South Korea. 2009.

[11] Cohen, W., Levinthal, D. Absorptive capacity: A new perspective on learning and innovation. Administrative Science Quarterly 1990;35(1), 128-152.

[12] Dorfman, P., House, R. Cultural influences on organizational leadership. In R. House, et al. (Eds.), Culture, leadership, and organizations. The GLOBE study of 62 societies . Sage Publications; 2004. p51-73.

[13] Rabotin, M. Deconstructing the successful global leader. T+D 2008;62(7), 54-59.

[14] Choi, J., Chang, J. Innovation implementation in the public sector: An integration of institutional and collective dynamics. Journal of Applied Psychology 2009;94(1), 245253.

[15] Lee, H., Lee, J., Lee, J., Choi, C. Time to change, time for change: How was time used to change a global company? Academy of Management Proceedings, August 2005.

[16] Park, S., Gil, Y. How Samsung transformed its corporate R\&D center. Research Technology Management 2006;49(4), 24-29.

[17] Hyundai Motor Company. Hyundai Motor Company PR Brochure 2008; 1-60.

[18] Wright, C., Suh, C., Leggett, C. If at first you don't succeed: globalized production and organizational learning at the Hyundai Motor Company. Asia Pacific Business Review 2009;15(2), 163-180.

[19] Thorpe, N. Employees take trips to understand other cultures. Automotive News 2005;79(6159), 24I-24I.

[20] Gebert, D., Boerner, S., Kearney, E. Cross-functionality and innovation in new product development teams: A dilemmatic structure and its consequences for the management of diversity. European Journal of Work \& Organizational Psychology 2006;15(4), 431458.

[21] El Amrani, R., Rowe, F., Geffroy-Maronnat, B. The effects of enterprise resource planning implementation strategy on cross-functionality. Information Systems Journal 2006;16(1), 79-104.

[22] Cohn, J., Katzenbach, J., \& Vlak, G. Finding and Grooming Breakthrough Innovators. Harvard Business Review 2008;86(12), 62-69.

[23] Gehani, R., Gehani, R. Mary Parker Follett's constructive conflict: A "psychological foundation of business administration" for innovative global enterprises. International Journal of Public Administration 2007;30(4), 387-404.

[24] Dooley, L., O'Sullivan, D. Structuring innovation: A conceptual model and implementation methodology. Enterprise and Innovation Management Studies 2001;2, 177 -194 . 
[25] Barnett, E., \& Storey, J. Narratives of learning, development and innovation: Evidence from a manufacturing SME. Enterprise and Innovation Management Studies 2001;2, 83 101.

[26] Byron, A. Microsoft goes after search ads hard. USA Today 2006, May 05.

[27] Porter, A. M. The case for holistic strategies. Purchasing 2004;133(5), p55-59.

[28] Hamel, G. Moon shots for management. Harvard Business Review 2009;87(2), 91-98.

[29] Westlund, R. Corporate social responsibility. Institutional Investor-International Edition 2008;33(3), 1-4. 